\title{
Control Mechanism of Rock Burst in the Floor of Roadway Driven along Next Goaf in Thick Coal Seam with Large Obliquity Angle in Deep Well
}

\author{
Yunhai Cheng, ${ }^{1,2}$ Jinchao Bai, ${ }^{1,2}$ Yankun Ma, ${ }^{1,2}$ Jian Sun, ${ }^{1,2}$ \\ Yunpei Liang, ${ }^{3}$ and Fuxing Jiang ${ }^{4}$ \\ ${ }^{1}$ The Key Laboratory of Safe and High-Efficiency Mining of Ministry of Education, Anhui University of Science and Technology, \\ Huainan, Anhui 232001, China \\ ${ }^{2}$ State Key Laboratory of Mine Disaster Prevention and Control Cultivation Base, Shandong University of Science and Technology, \\ Qingdao, Shandong 266590, China \\ ${ }^{3}$ School of Resources and Environmental Science, Chongqing University, Chongqing 400044, China \\ ${ }^{4}$ School of Civil and Environmental Engineering, Beijing University of Science \& Technology, Beijing 100083, China
}

Correspondence should be addressed to Yunhai Cheng; chengyunhai2005@126.com

Received 27 January 2015; Revised 10 May 2015; Accepted 11 May 2015

Academic Editor: Vadim V. Silberschmidt

Copyright (C) 2015 Yunhai Cheng et al. This is an open access article distributed under the Creative Commons Attribution License, which permits unrestricted use, distribution, and reproduction in any medium, provided the original work is properly cited.

This paper deals with the theoretical aspects combined with stress analysis over the floor strata of coal seam and the calculation model for the stress on the coal floor. Basically, this research presents the relevant results obtained for the rock burst prevention in the floor of roadway driven along next goaf in the exploitation of thick coal seam with large obliquity in deep well and rock burst tendency. The control mechanism of rock burst in the roadway driven along next goaf is revealed in the present work. That is, the danger of rock burst can be removed by changing the stress environment for the energy accumulation of the floor and by reducing the impact on the roadway floor from the strong dynamic pressure. This result can be profitable being used at the design stage of appropriate position of roadway undergoing rock burst tendency in similar conditions. Based on the analysis regarding the control mechanism, this paper presents a novel approach to the prevention of rock burst in roadway floor under the above conditions. That is, the return airway is placed within the goaf of the upper working face that can prevent the rock burst effectively. And in this way, mining without coal pillar in the thick coal seam with large obliquity and large burial depth (over a thousand meters) is realized. Practice also proves that the rock burst in the floor of roadway driven along next goaf is controlled and solved.

\section{Introduction}

The rock burst in roadway floor is a dynamic disaster during the process of coal mining [1]. The existing reports mainly focus on the explicit features, occurrence mechanism, and prevention measures of the rock burst in the near-horizontal coal floor [2-6]. However, there are few studies on the roadway floor in thick coal seam with large obliquity. And some studies have shown that the coal seams with large obliquity are more vulnerable to rock burst than slightly oblique or near-horizontal ones [7]. Thus, it is necessary to study the occurrence mechanism of coal seams with large obliquity.
Rock burst in roadway floor is a phenomenon of dynamic instability, the occurrence of which is related not only to the stress environment of the roadway, but also to the mechanical properties of the surrounding coal rocks. In particular, the hard formation underlying the coal seam has a significant influence on the occurrence of rock burst. For example, a rock burst accident occurred at 1410 upper entry of Huafeng Coal Mine on September 9, 2006, with the magnitude of 2.0. Microseismic monitoring revealed that the seismic source was located at $30 \mathrm{~m}$ ahead of the driving face and on the limestone $(f=7.0) 55 \mathrm{~m}$ below the floor of number 4 coal seam. Studies have shown that the hard floor will deform and accumulate energy because of the overburden pressure 
of the overlying strata and the mining-induced stress. When the accumulated energy is too large and cannot be released slowly due to the absence of buffer layer, rock burst will occur. In that case, the damage caused by the rock burst can be reduced by changing the conditions under which the energy is accumulated on the floor or by reducing the impact brought by energy release on the roadway floor.

According to statistics $[8,9]$, the methods commonly used in the prevention of rock burst of coal mines in China are divided into active danger relieving methods and local prevention methods. For the former, there are roof-break blasting, floor-break blasting, large-diameter drilling in coal seam and building of pressure relief groove on roadway floor, and so on; for the latter, there are roadway arrangement optimization and protective seam exploitation and so on. In deep well mining, the conventional local danger relieving methods have the defects of large workload of pressure relief engineering and complex working procedures due to high stress. Moreover, it is difficult to guarantee the effect of rock burst prevention in some cases. Therefore, the danger of rock burst cannot be prevented radically or reduced. To address these problems, in the present paper, the theory of elasticity is used to establish the mechanical model describing the relationship between the occurrence conditions of rock burst in the roadway floor of thick coal seam with large obliquity and the influence factors. With the model, the prevention mechanism of rock burst in the floor of roadway driven along next goaf is studied, so as to determine the relational equation between the stress corresponding to the floor damage and the energy. The influences of various parameters on the floor are characterized, which is of great significance for the optimization of arrangement of roadways driven along next goaf. According to the occurrence conditions of thick coal seam with large obliquity on 1412 fully-mechanized top-coal caving faces of Huafeng Coal Mine, the appropriate positions of roadway driven along next goaf are studied on the basis of stress theory and Mohr-Coulomb criterion. The research findings were then applied in field test, and the specific effect of rock burst prevention was evaluated and verified through microseismic monitoring and coal powder monitoring via drilling method.

\section{Control Mechanism of Rock Burst in the Roadway Floor}

2.1. Occurrence Mechanism of Rock Burst in Roadway Floor in the Coal Seam with Large Obliquity. The in situ stress is measured [10], and the results show that the horizontal component of in situ stress is 1.7-2.0 times that of the vertical component in deep layers of Huafeng Coal Mine, and the floor rocks are more affected by horizontal stress. During coal mining, the floor rocks bend upward and undergo deformation due to elastic recovery. When the interlaminar shear stress is exceeded, the floor will undergo shear damage. Thus, an inclining, thin, and fragile floor is formed between the immediate roof, coal seam, and the stable floor strata (Figure 1). In coal seam with large obliquity, the floor strata below the goaf are under the constraint of several factors, including undrived coal and the caving of gangues. Thus, the

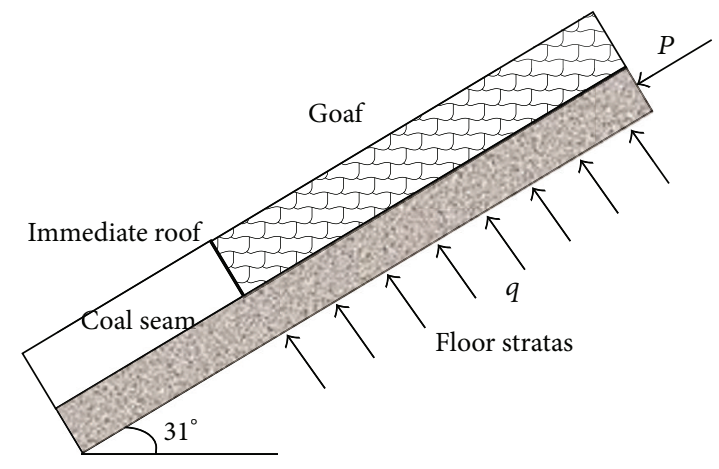

FIGURE 1: Composition schematic illustration of rock beam-pillar structure model.

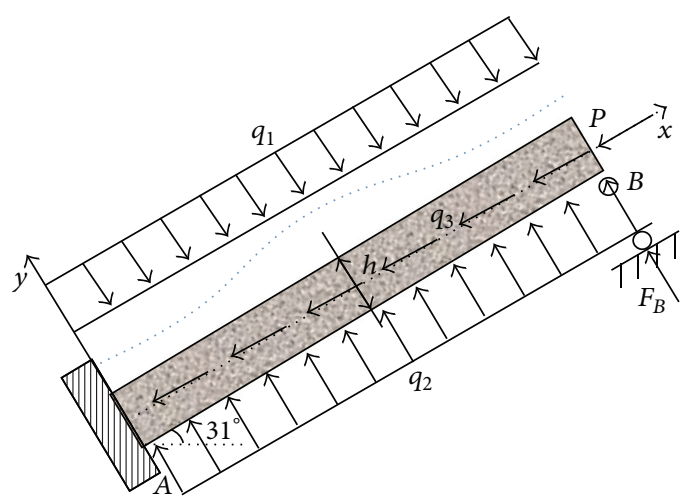

FIGURE 2: Mechanical model of rock burst in roadway floor caused by the instability of rock beam-pillar.

lower part of floor strata is far less affected by mining than the upper part. Then the strata under the immediate floor and those within a certain range below it are considered as the rock beam with lower end fixed and the upper end simply supported. Thus, the stress $P$ imposed by the shallow part of the strata on the deep part is regarded as the axial force on the beam. The elastic recovery $q_{2}$ of the strata below the floor due to the presence of goaf is regarded as the transverse force on the beam. Thus, the beam-pillar theory [11] is employed to analyze the damage of floor strata in the coal seam with large obliquity. The coal floor with unit width and thickness of $h$ is arranged along the dip direction of the coal seam to build the mechanical model shown in Figure 2. The stress status across the profile of floor strata in the dip direction is displayed, and the stress-induced instability is examined.

In the figure, $q_{1}$ is the sum of pressure caused by caved gangue in the goaf and the component of overburden pressure of overlying strata in $y$ direction; $q_{3}$ is the component of gravity stress of overlying strata in $x$ direction; $l$ is the length of the floor along the dip direction. According to static equilibrium conditions, the occurrence of bending deformation of the floor strata satisfies the following differential equation:

$$
E I \frac{d^{4} y}{d x^{4}}+\left[p+q_{3}(l-x)\right] \frac{d^{2} y}{d x^{2}}+q_{3} \frac{d y}{d x}=q_{1}-q_{2}
$$




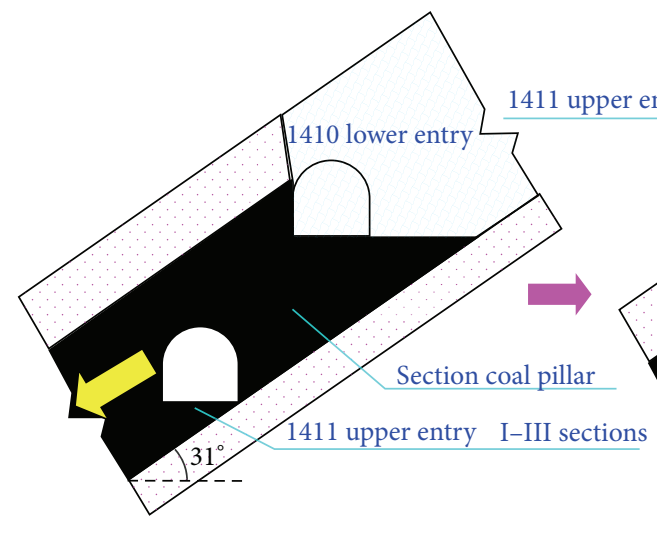

(a)

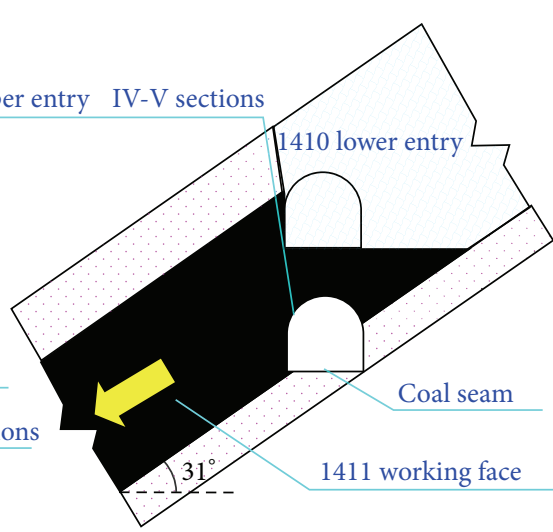

(b)

Figure 3: Arrangement of roadway driven along next goaf on 1411 working face. (a) Profile of the roadway with small coal pillars. (b) Profile of the roadway without coal pillars.

According to the boundary conditions of the established mechanical model (i.e., $x=0, y=0, d y / d x=0$ and $x=l, y=0, d y / d x=0$ ), the trigonometric series solution of the twisted curve representing this differential equation is obtained:

$$
y=\sum_{n=1}^{\infty} a_{n}\left(1-\cos \frac{2 n \pi}{l} x\right) .
$$

The total energy stored due to deformation is

$$
\begin{aligned}
U & =\frac{1}{2} \int_{0}^{l}\left[E I\left(\frac{d^{2} y}{d x}\right)^{2}-q_{3}(l-x)\left(\frac{d y}{d x}\right)^{2}\right. \\
& \left.-p\left(\frac{d y}{d x}\right)^{2}-\left(q_{1}-q_{2}\right) y\right] d x .
\end{aligned}
$$

Substituting (2) into (3), there is

$$
U=\sum_{n=1}^{\infty}\left[\left(\frac{4 n^{4} \pi^{4}}{l^{3}}-\frac{p n^{2} \pi^{2}}{l}-\frac{q_{3} n^{2} \pi^{2}}{2}\right) a_{n}{ }^{2}-q_{1 n} a_{n}\right] .
$$

If $\left(q_{1}-q_{2}\right)$ is a constant, then according to least energy principle,

$$
a_{n}=\frac{\left(q_{1}-q_{2}\right) l^{4}}{8 E \operatorname{In}^{4} \pi^{4}-2 p n^{2} \pi^{2} l^{2}-q_{3} n^{2} \pi^{2} l^{3}},
$$

where $n \geqslant 0$ and is an integer. When $n=1$, the maximum tensile stress borne by the floor is calculated as

$$
\begin{aligned}
\sigma_{\max } & =E \varepsilon_{\max }=E \frac{h}{R}=\frac{4 E \pi^{2} a_{1} h}{l^{2}} \\
& =\frac{4 E h\left(q_{1}-q_{2}\right) l^{2}}{8 E I \pi^{2}-2 p l^{2}-q_{3} l^{3}} .
\end{aligned}
$$

The strain energy stored by the bending deformation of the floor is calculated as

$$
U_{1}=\frac{\sigma_{\max }^{2}}{2 E}=\frac{8 E h^{2}\left(q_{1}-q_{2}\right)^{2} l^{4}}{\left(8 E I \pi^{2}-2 p l^{2}-q_{3} l^{3}\right)^{2}} .
$$

It can be known from the strength condition that when $\sigma_{\max }>\left[\sigma_{t}\right]$, the hard strata of the floor will be damaged abruptly, releasing the stored strain energy. When the energy cannot be released slowly, the rock burst in roadway floor will occur. It is known from (7) that, for a specific coal rock, the values of $E$ and $h$ are fixed. Thus, the magnitude of elastic strain energy released by the rupture of the floor strata in the research area depends on the surrounding rock stress. The stress is composed of horizontal stress $P, q_{3}$ and normal stress $\left(q_{1}-q_{2}\right)$. The weaker the surrounding rock stress, the smaller the energy accumulated in the hard strata of the floor, and the smaller the impact on the roadway floor in case of rock burst. According to the literature [12], the surrounding rock stress decreases near the excavation region. The floor is free from the action of the horizontal stress. Moreover, the loose and fragmented region of plastic failure on the floor can cushion and absorb the energy released by the floor. This will help prevent the rock burst in the roadway floor.

Thus, the core of preventing the rock burst in the roadway floor is to get away from the region with increasing stress. The stress concentration on the roadway should also be prevented, so as to reduce the influence of dynamic pressure on the roadway floor and hence the risk of rock burst.

\subsection{Analysis of the Influence Factors in Rock Burst Prevention.} In field applications, the factors such as floor lithology and mining conditions are given. So the position of roadway driven along next goaf is the primary factor influencing the effect of prevention of rock burst in the roadway floor. A case analysis is carried out on 1411 working face of Huafeng Coal Mine to discuss the influence of the position of roadway on the effect of rock burst prevention.

Driving is performed in the 1411 upper entry of Huafeng Coal Mine in 5 segments. For segments 1 to 3, as shown in Figure 3(a), the roadway layout with small coal pillar is employed. Under the protection of number 1 and number 6 upper and lower protective seams, the auxiliary measures such as roof breaking, floor breaking, and large-diameter drilling for pressure relief are adopted. These measures are effective for ensuring the smooth and safe stopping on the 
TABLE 1: The location statistics of mine tremor by using microseismic monitoring.

\begin{tabular}{lccccccc}
\hline \multirow{2}{*}{ Number } & \multicolumn{4}{c}{ Coordinate $\mathrm{m}$} & Distance from the working face & Horizon & Seismic source \\
& $X$ & $Y$ & $Z$ & & & \\
\hline 1 & 3439 & 4854 & -955 & $11 \mathrm{~m}$ behind the working face & $4 \mathrm{~m}$ below the floor & $52 \mathrm{~m}$ below the upper entry & 1.5 \\
2 & 3393 & 4925 & -930 & $45 \mathrm{~m}$ in front of the working face & $2 \mathrm{~m}$ below the floor & $11 \mathrm{~m}$ below the upper entry & 1.3 \\
3 & 3402 & 4869 & -936 & $15 \mathrm{~m}$ behind the working face & $8 \mathrm{~m}$ below the floor & $17 \mathrm{~m}$ below the upper entry & 1.3 \\
4 & 3382 & 5004 & -921 & $88 \mathrm{~m}$ in front of the working face & $3 \mathrm{~m}$ below the floor & $3 \mathrm{~m}$ below the upper entry & 1.9 \\
5 & 3478 & 5337 & -953 & $260 \mathrm{~m}$ in front of the working face & $2 \mathrm{~m}$ below the floor & $52 \mathrm{~m}$ below the upper entry & 1.6 \\
6 & 3412 & 5101 & -940 & $48 \mathrm{~m}$ behind the working face & $5 \mathrm{~m}$ below the floor & $14 \mathrm{~m}$ below the upper entry & 1.6 \\
\hline
\end{tabular}

working face, as indicated in practice. However, the roadway driven along next goaf is likely to suffer from rock burst. For example, from January to February of 2011, mine tremors of 1.9 and 2.1 magnitudes occurred in 1411 upper entry, with the energy of $9.4 \times 10^{6} \mathrm{~J}$ and $2.2 \times 10^{7} \mathrm{~J}$, respectively. The two mine tremors are localized to $63 \mathrm{~m}$ behind the working face and $2 \mathrm{~m}$ below the floor, and $13 \mathrm{~m}$ behind the driving face and $3 \mathrm{~m}$ below the floor, respectively.

From segments 4 to 5, as shown in Figure 3(b), due to the pinch-out of the protective layer of number 1 coal seam, the upper entry is subjected to high stress. This is the region where the stress recovery belt of number 6 protective seam is superimposed with the laterally abutment area of stress concentration on 1410 working faces. Thus, the roadway layout without coal pillar is employed. That is, the upper entry is located below the pressure-relief region of the floor of transportation lane on the upper working face. Thus, pressure relief is unnecessary for the roof, floor, and the coal seam to achieve stopping. However, the floor of the roadway driven along next goaf is likely to suffer from the rock burst, as shown in Table 1.

The most important reason for the occurrence of rock burst is high stress concentration $[13,14]$. The roadways with small coal pillar or no coal pillar are free from the impact of driving-induced peak pressure since they are located in low stress field. But the energy of rock burst in the roadway floor is supplied by its stress. Therefore, the stress distribution of floor strata should also be considered to achieve a reasonable arrangement of roadways driving along the goaf.

In order to discuss the influence of different roadway arrangement on the effect of floor impact prevention, the geological conditions of 1412 working face of Huafeng Coal Mine and the mining conditions of the nearby working face are considered. The mechanical model of floor under stress is constructed to determine the appropriate position of roadway driven along next goaf by comprehensively considering the stress distribution of the roadway roof and floor.

2.2.1. Structural Model of Lateral Strata Overlying the Goaf and the Distribution of the Bearing Pressure. 1411 goaf lies on one side of the 1412 working face and the undrived coal on the other side. According to the literature [15], the irregular collapse of overlying strata stops only when the goaf is filled by coal and waste rocks. Thus, the thickness of the immediate roof of 1412 working face is $M_{z}=\left(h-S_{A}\right) /\left(K_{A}-1\right)=$ $16 \mathrm{~m}$, where $h$ is the mining height with the value of $6.4 \mathrm{~m}$;
$K_{A}$ is the bulking factor with the value of $1.3 ; S_{A}$ is the settlement of uncollapsed strata at the position where the gangue is touched. Before the lateral weighting of the main roof, $S_{A}=0$. Hence, the strata comprising the immediate roof from bottom to top are as follows: $2.5 \mathrm{~m}$ thick siltstone (10), $9.2 \mathrm{~m}$ thick fine-grained sandstone (9), $1.9 \mathrm{~m}$ thick finegrained silty sandstone (8), and $2.4 \mathrm{~m}$ thick medium-grained sandstone (7)). Since the overlying $7.3 \mathrm{~m}$ thick mediumgrained sandstone (6) shows irregular collapse with a small fracture spacing, this layer is also considered as an immediate roof. The first weighting step of main roof is measured as $51 \mathrm{~m}$; the unidirectional tensile strength is $1.96 \mathrm{MPa}$; the thickness of main roof of 1412 working face is $M_{E O}=C_{O}{ }^{2} \gamma_{E} / 2[\sigma]_{T}=$ $18 \mathrm{~m}$, where $C_{O}$ is the first weighting step of the main roof; $\gamma_{E}$ is the volume weight of main roof strata, which is $2.7 \mathrm{t} / \mathrm{m}^{3} ;[\sigma]_{T}$ is the unidirectional tensile strength of main roof strata. Therefore, the main roof consists of the following strata from bottom to top: $2.2 \mathrm{~m}$ thick fine-grained silty sandstone (5), $9.5 \mathrm{~m}$ thick siltstone (4)), $1.3 \mathrm{~m}$ thick claystone (3), $5.0 \mathrm{~m}$ thick medium-grained sandstone (2), and $2.0 \mathrm{~m}$ thick claystone (1)). During field survey, the weighting of main roof appears periodically in lateral direction and the fracture spacing is equal to the step of periodic weighting. This indicates the formation of rock beam structure on the main roof. For the fully-mechanized top-coal caving face 1411, the load borne by its caving support is smaller than the theoretical value of $539.2 \mathrm{kN} / \mathrm{m}^{2}$ during the stopping. Thus, the overlying $7.3 \mathrm{~m}$ thick medium-grained sandstone provides a load-bearing structure, which constitutes a structural protection together with the main roof. Therefore, the $7.3 \mathrm{~m}$ thick medium-grained sandstone and the $16 \mathrm{~m}$ thick strata are divided into upper immediate roof and lower immediate roof, respectively. Then the structural model of lateral strata overlying the 1411 goaf is built, as shown in Figure 4.

It is precisely due to the protection provided by the main roof and the upper immediate roof that the mining roadway on the working face does not have to bear all the weight of the overlying strata. Such structural protection obeys the key strata theory for strata control [16]. As the working face is driven forward, the overlying strata undergoes constant movement. The resulting structure undergoes the process from formation, instability, to reformation, until the goaf is gradually compacted. During this process, the weight of the overlying strata shift constantly towards the deep part of the coal, causing the stress to concentrate in deep part of the coal. As a result, the stress on the margin of the coal and in the 


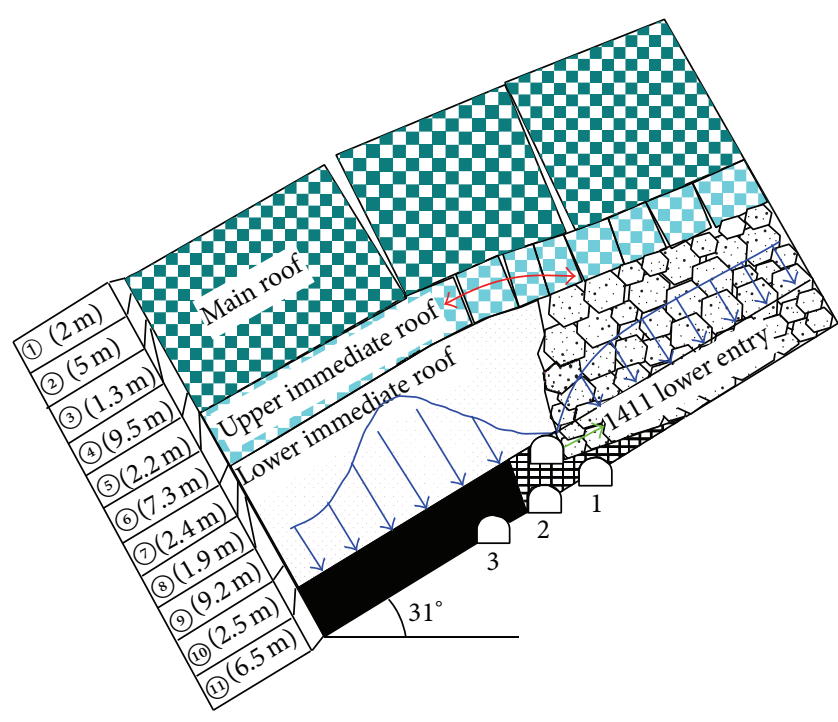

(1) Roadway without coal pillar

(2) Roadway without coal pillar

(3) Roadway with small pillar

FIGURE 4: Structural model of lateral strata overlying the roadway driven along next goaf.

goaf decreases. As shown in Figure 4, the roadway driven along next goaf is located in the region where the stress is decreasing.

2.2.2. Stress Calculation Model for the Floor. The research on the floor stress distribution is especially important for a reasonable roadway arrangement and the prevention of rock burst. According to elastic mechanics theory, when one concentrated force acts on the plane of semi-infinite body, the stress component of any point in the semi-infinite body can be obtained. Although rock is heterogeneous and discontinuous, the stress distribution in the rock body can be solved by analytical method if the floor of the coal seam is considered as a semi-infinite body. Many scholars have carried out relevant researches and obtained some achievements. For example, Wang et al. [17] and Meng et al. [18] established the mechanical model of the floor of coal seam by analyzing the stress distribution of mine. In their study, the floor stress distribution and the maximum failure depth were calculated theoretically and compared with the field survey. The results indicated small errors and high reliability.

The analytic method is effective in stress calculation of coal floor. According to the theory of elasticity, the floor of 1412 working face is considered as a semi-infinite body. Based on the distribution of lateral bearing pressure on the working face, the mechanical model of floor of roadway driven along next goaf is built, as shown in Figure 5, where regions I, II, and IV are the regions of plasticity, elasticity, and pressure relief, with the length of $L_{1}, L_{2}$, and $L_{4}$, respectively. Regions III and $\mathrm{V}$ are the regions of in situ stress, with the length of $L_{3}$ and

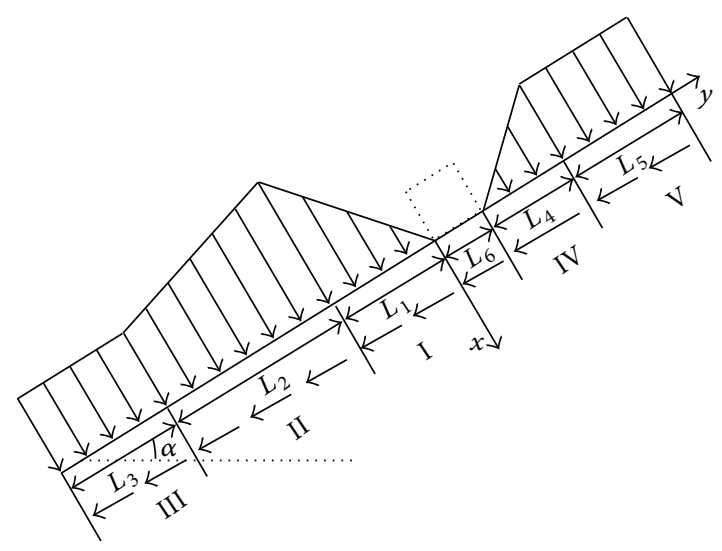

Figure 5: Mechanical model of floor under stress.

$L_{5}$, respectively; $\alpha$ is the dip angle of the coal seam. $L_{6}$ is the width of the roadway.

Unlike the near-horizontal coal seam, the coal seam with large obliquity has an additional tangential component along the dip direction, the value of which is nonignorable. The lateral bearing pressure of the coal seam is decomposed into the vertical force in parallel with the dip direction of the coal seam and the transverse force vertical to the dip direction of the coal seam. As shown by the theory of elasticity, the tiny transverse force $q d \eta$ acting on the boundary of the semiinfinite body can cause the following components of stress at any point of floor strata:

$$
\begin{gathered}
\sigma_{x}=-\frac{2}{\pi} \int_{-b}^{a} \frac{q x^{3} d \eta}{\left[x^{2}+(y-\eta)^{2}\right]^{2}}, \\
\sigma_{y}=-\frac{2}{\pi} \int_{-b}^{a} \frac{q x(y-\eta)^{2} d \eta}{\left[x^{2}+(y-\eta)^{2}\right]^{2}} \\
\tau_{x y}=-\frac{2}{\pi} \int_{-b}^{a} \frac{q x^{2}(y-\eta) d \eta}{\left[x^{2}+(y-\eta)^{2}\right]^{2}} .
\end{gathered}
$$

The vertical force $q d \eta$ acting on the boundary of semiinfinite body can cause the following components of stress at any point in floor strata:

$$
\begin{gathered}
\sigma_{x}=-\frac{2}{\pi} \int_{-b}^{a} \frac{q \tan \alpha x^{2}(y-\eta) d \eta}{\left[x^{2}+(y-\eta)^{2}\right]^{2}}, \\
\sigma_{y}=-\frac{2}{\pi} \int_{-b}^{a} \frac{q \tan \alpha(y-\eta)^{3} d \eta}{\left[x^{2}+(y-\eta)^{2}\right]^{2}}, \\
\tau_{x y}=-\frac{2}{\pi} \int_{-b}^{a} \frac{q \tan \alpha x(y-\eta)^{2} d \eta}{\left[x^{2}+(y-\eta)^{2}\right]^{2}} .
\end{gathered}
$$

Among them, $a, b$ are the upper and lower limits of integral region, respectively; $\eta$ is integral variable (Figure 6). When using these formulae, the floor load intensity $q$ of different region is expressed as the function of $\eta$. The 


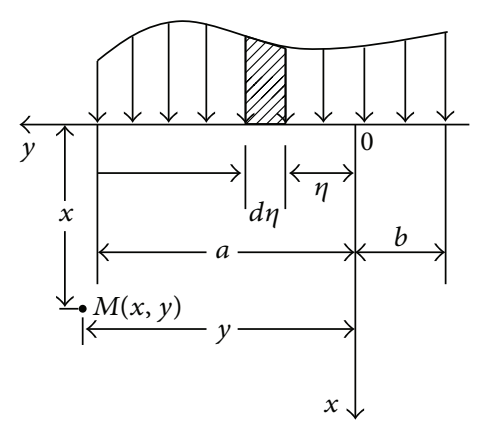

(a) Lateral load

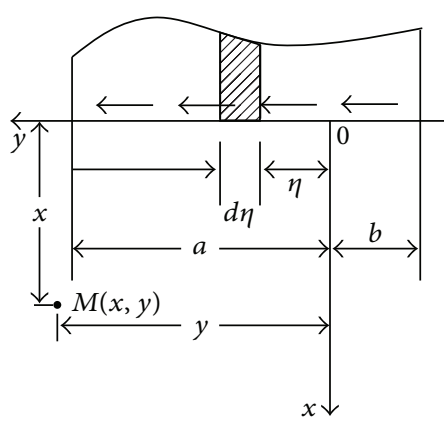

(b) Longitudinal load

FIgURE 6: Schematic diagram of stress calculation of coal seam floor with distributed load.

results are introduced into (8) and (9) to calculate the stress components. By superposition, the stress components at any point in the floor strata are obtained. The loads of each region are calculated as follows.

Region I is as follows:

$$
\begin{aligned}
q_{1}= & \gamma H \cos \alpha \\
& +\frac{\left(k_{1}-1\right) \gamma H \cos \alpha+k_{1} L_{1} \gamma \sin \alpha \cos \alpha}{-L_{1}} \eta .
\end{aligned}
$$

Region II is as follows:

$$
\begin{aligned}
q_{2}= & k_{1} \gamma H \cos \alpha+k_{1} L_{1} \gamma \sin \alpha \cos \alpha \\
& +\frac{\left[\left(k_{1}-1\right) L_{1}-L_{2}\right] \gamma \sin \alpha \cos \alpha}{L_{2}}\left(\eta+L_{1}\right) \\
& +\frac{\left(k_{1}-1\right) \gamma H \cos \alpha}{L_{2}}\left(\eta+L_{1}\right) .
\end{aligned}
$$

Regions III, IV, and V are as follows:

$$
q_{3,4,5}=\gamma H \cos \alpha-\gamma \sin \alpha \cos \alpha \eta \text {. }
$$

According to the field observation of mine pressure and the literature [19], the parameters are set as follows: $k_{1}=1.7$, $L_{1}=35 \mathrm{~m}, L_{2}=110 \mathrm{~m}, L_{3}=L_{5}=20 \mathrm{~m}, L_{4}=15 \mathrm{~m}$, and $L_{6}=4.5 \mathrm{~m}$, where $k_{1}$ is the maximum stress concentration factor. Substituting the load of each region into (8) and (9), the diagram of stress distribution of the floor is plotted, as shown in Figure 7.

It is known from the figure that after the mining of 1411 working face, the vertical stress at any point in the strata below the floor shows an asymmetrical distribution pattern (increasing with depth) along the dip direction of the coal seam. Among them, the vertical stress at the distance of $0 \mathrm{~m}$ from the floor is also 0 . The region from the location $10 \mathrm{~m}$ ahead of the coal wall to that $15 \mathrm{~m}$ behind the coal wall (goaf) is the region of pressure relief for floor rocks under the action of lateral bearing pressure. The pressure relief of the floor becomes more obvious at the place closer to the goaf and to the shallow layer. The minimum stress factors are 0.556 ,

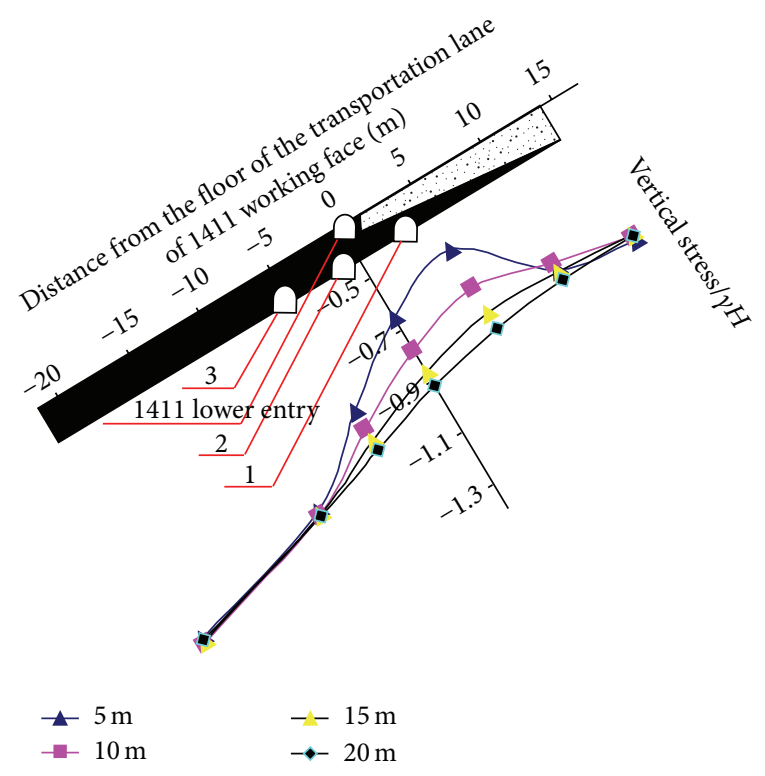

FIGURE 7: Changes of vertical stress along the dip direction at different depth.

0.707 , and 0.816 at the depth of 5,10 , and $15 \mathrm{~m}$ below the floor, respectively. They are located at $2 \mathrm{~m}$ and $0 \mathrm{~m}$ behind the goaf and $5 \mathrm{~m}$ ahead of the coal wall, respectively. At this time, the stress curve has the minimum slope. Moreover, the stress values of the three positions decrease at the shallower layer.

Since the surrounding rock stress is lower in the pressure relief region and the roadway is easier to be maintained, there are 3 possible positions of roadway driven along next goaf: mining without coal pillar on the same vertical surface in 1411 upper entry, mining with small coal pillars at $5 \mathrm{~m}$ ahead of the coal wall, and mining with coal pillars $2 \mathrm{~m}$ behind the goaf.

The source of rock burst of the floor is the concentrated stress in the elastic region of floor. After the excavation of roadway, the in situ rock stress field undergoes certain variations. The vertical stress begins to transfer to two sides, while the horizontal stress transfers to the roof and floor of coal mine, reaching the maximum in the elastic region of the floor. Therefore, horizontal stress plays an important role in the occurrence of rock burst in the floor. According to the theory 
TABLE 2: Strata underlying the coal seam and its physical and mechanical parameters.

\begin{tabular}{|c|c|c|c|c|c|}
\hline Lithology & Thickness/m & $\begin{array}{c}\text { Internal friction } \\
\text { angle } /^{\circ}\end{array}$ & $\begin{array}{l}\text { Uniaxial tensile } \\
\text { strength/MPa }\end{array}$ & $\begin{array}{l}\text { Uniaxial compressive } \\
\text { strength/MPa }\end{array}$ & $\begin{array}{c}\text { Protodyakonov } \\
\text { coefficient/f }\end{array}$ \\
\hline Siltstone & 1.7 & - & - & 50.4 & 3.5 \\
\hline Medium-grained sandstone & 4.2 & 35.8 & 10.07 & 113.7 & 5.0 \\
\hline Siltstone & 4.8 & 45.8 & 5.06 & 35.6 & 3.5 \\
\hline Coarse-grained sandstone & 3.5 & 41.8 & 6.73 & 85.5 & 5.0 \\
\hline Siltstone & 4.8 & 51.8 & 6.47 & 62.1 & 5.5 \\
\hline Medium-grained sandstone & 5.2 & 47.8 & 8.27 & 128.3 & 5.0 \\
\hline
\end{tabular}

of rock mass mechanics, the horizontal stress and vertical stress in the elastic region of the floor satisfy the following relation, $\sigma_{y}=\lambda \sigma_{z}$, that is a positive correlation. Thus, under a given lateral pressure coefficient, the horizontal stress of the floor increases linearly with the increasing vertical stress. This increases the risk of rock burst in the floor of roadway. Literature [20] analyzed the effect of horizontal stress on the rock burst of roadway floor under different lateral pressure coefficients and dynamic loads. The results showed that, as the lateral pressure coefficient $(\lambda<2)$ increased, the high stress difference on the floor (the difference between vertical stress and horizontal stress) increased linearly, and rock burst of the floor was intensified. Therefore, the analysis based on vertical stress is reliable.

\subsubsection{Impact on the Floor of Roadway Driven along Next Goaf.} The failure of rock body under triaxial stress satisfies the Mohr-Coulomb criterion:

$$
\sigma_{1}=R_{c}+\frac{1+\sin \varphi}{1-\sin \varphi} \sigma_{3}
$$

where $\sigma_{1}$ and $\sigma_{3}$ are the limiting principal stresses of the rock body $\left(\sigma_{1}>\sigma_{3}\right) ; \varphi$ is the internal friction angle of the floor strata; $R_{c}$ is the uniaxial compressive strength of the rock. The principal stress is expressed as

$$
\begin{gathered}
\sigma_{1}=\frac{\sigma_{x}+\sigma_{y}}{2}+\sqrt{\left(\frac{\sigma_{x}-\sigma_{y}}{2}\right)^{2}+\tau^{2}{ }_{x y}}, \\
\sigma_{3}=\frac{\sigma_{x}+\sigma_{y}}{2}-\sqrt{\left(\frac{\sigma_{x}-\sigma_{y}}{2}\right)^{2}+\tau^{2}{ }_{x y} .}
\end{gathered}
$$

Let $F(x, y)=\sigma_{1}-((1+\sin \varphi) /(1-\sin \varphi)) \sigma_{3}$. According to Table 2, when $F(x, y)>R_{c}$, the failure of rocks occurs.

The stress components obtained from (8) and (9) are introduced into the above formula to judge the failure of rocks at different positions of the floor. Thus, the failure mode of the entire floor under the action of bearing pressure along the dip direction is obtained, as shown in Figure 6. It is determined that the siltstone and the medium-grained sandstone from top to bottom of the floor strata all show failure, with the maximum failure depth of $6.9 \mathrm{~m}$.

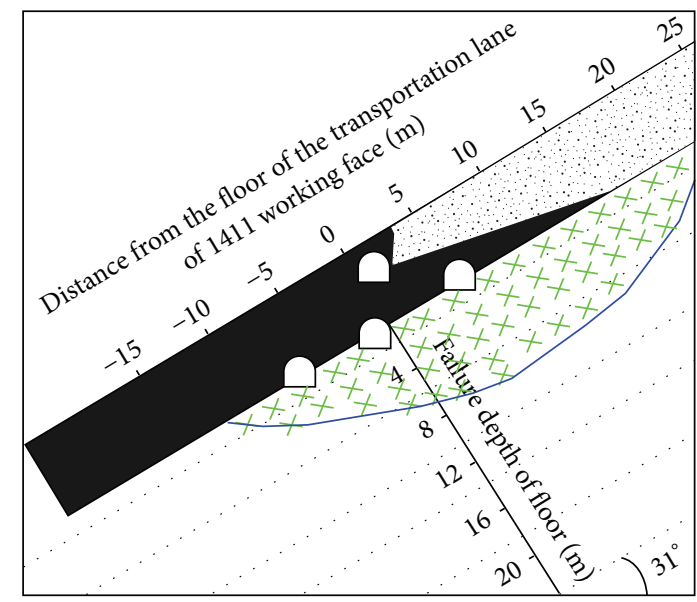

FIGURE 8: Failure curve of floor strata along the dip direction.

Under different arrangement of roadways driven along next goaf, the stress distribution of the rocks surrounding the roadway is obtained (Figure 7), and the failure mode of the floor strata is also known (Figure 8). The results show that the vertical stress of floor at positions 2 and 3 does not differ obviously, and the effect of pressure relief is not so obvious compared with that at position 1 . The depth of plastic failure at position 1 is greater than that at positions 2 and 3 .

As the energy is released abruptly by rock burst, the energy dissipated by the deformation of the surrounding rocks is limited. The roadway is inevitably subject to the impact. If the instantaneity of energy dissipation and release during doing work outward is ignored, then the work done by the impact force generated by the failure of floor strata to the rock body is expressed as

$$
V=F h
$$

where $F$ is the force acting on the roadway floor during the failure of floor strata; $h$ is the failure depth of floor strata. According to the law of conservation of energy, the work $V$ done by the external force to the rock body is equal to the deformation energy $U$ of the rock body; that is, $U=F h$. It can be seen that the greater the depth of plastic failure of roadway floor in the direction vertical to the floor, the smaller the relative resistance encountered by the roadway floor in case of impact. 


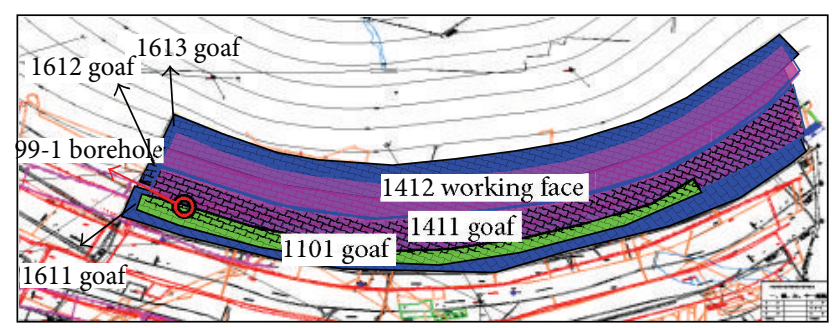

FIGURE 9: Synthetic plan view of the 1412 fully-mechanized top-coal caving face.

\section{Engineering Verification}

3.1. Production Conditions of the Working Face. The 1412 fully-mechanized top-coal caving face of Huafeng Coal Mine (Figure 9) has a burial depth of 1130-1220 m. The upper number 1 coal seam has already been mined. Only the 1613 working face of number 6 coal seam below is mined in advance as the protective seam. Obliquely above the working face is the 1411 working face that has already been mined. Obliquely below is the undrived coal. The average thickness of the coal seam is $6.4 \mathrm{~m}$ and the dip angle is $31^{\circ}$. The results of the assessment of rock burst tendency of the coal rock show that the coal seam and the immediate roof have a weak rock burst tendency, while the immediate floor has a strong rock burst tendency.

It can be seen from the bar graph of 99-1 borehole near 1412 working face that below the coal seam there are several sets of hard strata with large strength (Table 2). According to the key stratum theory, the fracture of these hard strata is very likely to induce dynamic disasters such as mine tremor and rock burst. It is known from Table 1 that the mine tremors are localized to $2-8 \mathrm{~m}$ below the floor of the upper entry, where there exists a hard stratum with large strength (i.e., $4.2 \mathrm{~m}$ medium-grained sandstone). Thus, the mine tremors occurring on the working face are attributed to the fracture of hard rock. The working face of our interest is controlled by the syncline structure, with the average mining depth of nearly $1200 \mathrm{~m}$, and there is no protective seam. If the layout without coal pillars is used for the mining of 1411 working face, it is expected that the dynamic phenomena will be more intense in the return airway. The condition is not favorable to prevent the rock burst in the roadway floor. Thus, the rock burst prevention design should be carried out.

\subsection{Determination of Position of Floor of Roadway Driven} along Next Goaf and the Effect of Rock Burst Prevention. Based on the prevention mechanism of rock burst in the floor of roadway driven along next goaf, the schemes of mining with small coal pillars and without coal pillars are analyzed synthetically. Meanwhile, the 1412 return airway is placed in the goaf of the 1411 working face (Figures 4 and 2 ). In this way, the upper entry of the working face to be mined is located in the pressure relief region below the 1411 goaf. The surrounding rock stress in the roadway decreases, and the plastic failure covers a large range. Therefore, the floor is subject to a smaller impact, and the probability of

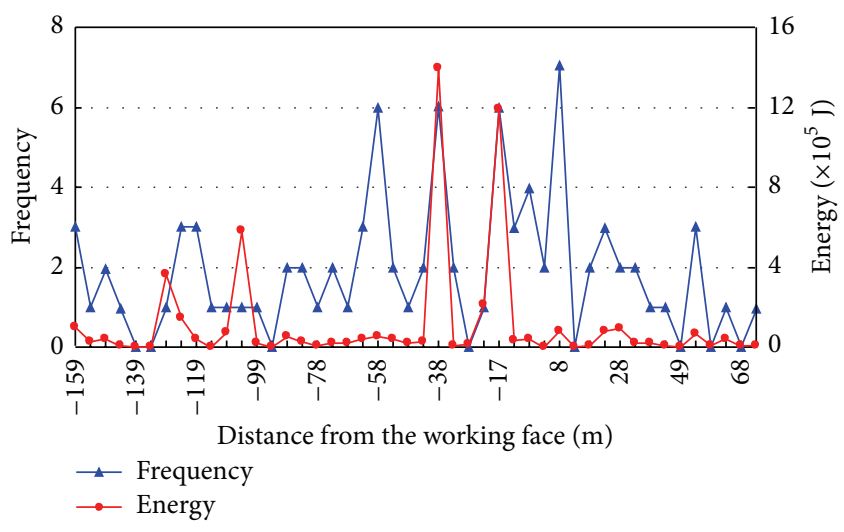

FIGURE 10: Statistics of microseismic events at an interval of $5 \mathrm{~m}$ on the fixed driving face.

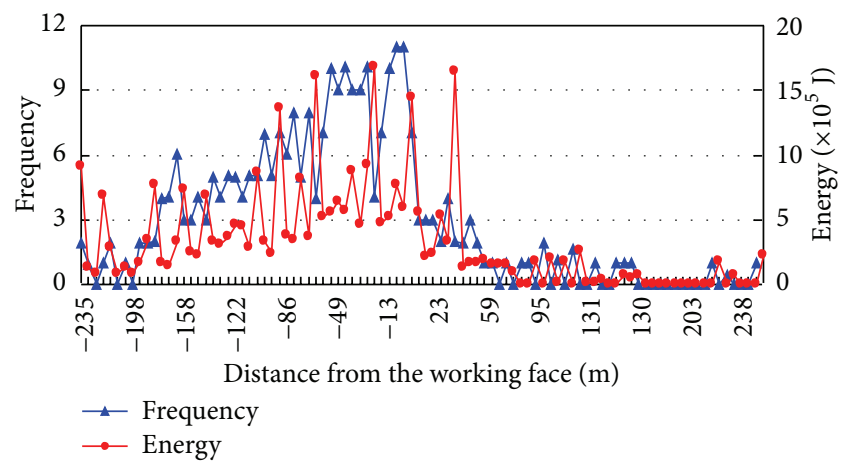

FIGURE 11: Statistics of microseismic events at an interval of $5 \mathrm{~m}$ on the fixed stopping face.

rock burst in the roadway is greatly reduced. In order to verify the prevention effect of rock burst in the roadway floor, microseismic monitoring was utilized to analyze the microseismic events during the driving of 1412 upper entry and during the stopping.

The specific regions of energy release through the microseismic events during the driving and stopping of the 1412 working face were first determined. The microseismic events were localized to the working face, as shown in Figures 10 and 11.

It can be seen from Figure 10 that the roadway is stable during the driving stage, with less occurrence of microseismic events and less energy released. The distribution of microseismic events is scattered, and the events are rare ahead of the working face. There are no regions of concentrated fracture or concentrated energy release. The occurrence probability of seismic events with large energy release is effectively reduced. Moreover, since it is far away from the driving face, the danger of rock burst in the working face is removed.

It can be seen from Figure 11 that the daily occurrence frequency of microseismic events during the stopping process is mostly lower than 10 times, with the average of 4.5 times and a small fluctuation. Although the energy released by microseismic events increases by a certain extent, most of the energy comes from the goaf behind the working face. Thus, 
TABLE 3: Coal powder amounts at different borehole depths of 1412 working face.

\begin{tabular}{lllllllll}
\hline Borehole depth/m & $2 \mathrm{~m}$ & $3 \mathrm{~m}$ & $4 \mathrm{~m}$ & $5 \mathrm{~m}$ & $6 \mathrm{~m}$ & $7 \mathrm{~m}$ & $8 \mathrm{~m}$ & $9 \mathrm{~m}$ \\
\hline Coal powder amount $/ \mathrm{kg}$ & & & & & & & & \\
Standard coal power & 1.94 & 2.18 & 2.20 & 2.07 & 2.27 & 2.16 & 2.15 & 2.10 \\
Driving period & 2.10 & 2.30 & 2.41 & 2.23 & 2.20 & 2.46 & 3.39 & 2.27 \\
Stopping period & 2.35 & 2.43 & 2.58 & 3.14 & 2.47 & 2.34 & 2.45 & 2.76 \\
\hline
\end{tabular}

the danger of rock burst in the working face can be removed effectively.

As shown by the data of microseismic monitoring, the arrangement of the roadway driven along next goaf is favorable to remove the danger of rock burst in the floor. In order to determine the degree of the danger of rock burst, the coal powder monitoring via drilling method was performed. The effect of prevention of rock burst in the roadway driven along next goaf was further evaluated. The coal powder amount reaching the danger threshold was calibrated by reference to the measured coal powder amounts at different depths: $2.91 \mathrm{~kg} / \mathrm{m}$ at $2-3 \mathrm{~m}$ borehole depth, $4.40 \mathrm{~kg} / \mathrm{m}$ at $4-$ $6 \mathrm{~m}$ borehole depth, and $8.40 \mathrm{~kg} / \mathrm{m}$ at $7-9 \mathrm{~m}$ borehole depth. As shown in Table 3, the measured coal powder amounts during the driving and stopping period are all smaller than the danger threshold, indicating no rock burst danger in the roadway driven along next goaf.

\section{Conclusion}

(1) The mechanical model of rock burst in the roadway floor of thick coal seam with large obliquity is built. The occurrence conditions of rock burst and the influence factors are then analyzed using this model. When the stress of floor strata exceeds the limit, the hard floor strata will be damaged, inducing the rock burst. In the meantime, the lower the surrounding rock stress (including the horizontal stress and the normal stress), the smaller the energy stored in the hard floor strata, and hence the lower the impact on the floor during the rock burst. The prevention mechanism of rock burst in the roadway driven along next goaf is revealed in the present work. Thus, the danger of rock burst can be removed by changing the stress environment for the energy accumulation of the floor and by reducing the impact on the roadway floor from the strong dynamic pressure.

(2) The mechanical model of floor under stress in coal seam with large obliquity is built. Based on the stress theory and Mohr-Coulomb criterion, the stress distribution curve of coal floor at different depths is plotted. The failure depths of floor at different positions are calculated. Moreover, the relationship of the impact force on the floor with the vertical distance between roadway and the damaged floor strata is provided under different arrangements of roadway driven along next goaf. That is, the larger the depth of plastic failure in the direction vertical to the roadway floor, the smaller the relative resistance on the roadway floor.

(3) Based on the analysis of the mechanism of rock burst control, 1412 return airway is placed in the 1411 goaf of the upper working face. Thus, the mining without coal pillars is realized in thick coal seam with large obliquity in deep well. Microseismic monitoring and coal powder monitoring by drilling method were performed to confirm that the roadway floor was free from the danger of rock burst.

\section{Conflict of Interests}

The authors declare that there is no conflict of interests regarding the publication of this paper.

\section{Acknowledgments}

The authors acknowledge National Natural Science Foundation Project (Grant no. 51174002) and Open Foundation of State Key Laboratory of Mine Disaster Prevention and Control Cultivation Base, Shandong University of Science and Technology, Qingdao, Shandong 266590, China (Grant no. MDPC2012KF02).

\section{References}

[1] L. M. Dou and X. Q. He, Rockburst Control Theory and Technology, China University of Mining and Technology Press, Xuzhou, China, 2001.

[2] X.-F. Xu, L.-M. Dou, J. Liu, X.-H. Cui, Y.-L. Zhang, and X.-Y. Yao, "Research of reasons and controlling for floor burst in coal mine roadway," Rock and Soil Mechanics, vol. 31, no. 6, pp. 19771982, 2010.

[3] A.-Y. Cao, L.-L. Zhu, Z.-Y. Du, J.-G. Liu, H. Wang, and Y. Wang, "Control principle and pressure-relief technique of rock burst occurred in roadway floor," Journal of Mining \& Safety Engineering, vol. 30, no. 6, pp. 848-855, 2013.

[4] L. Driad-Lebeau, F. Lahaie, M. Al Heib, J. P. Josien, P. Bigarré, and J.-F. Noirel, "Seismic and geotechnical investigations following a rockburst in a complex French mining district," International Journal of Coal Geology, vol. 64, no. 1-2, pp. 66-78, 2005.

[5] T. Li, W. Wang, J. W. Xie et al., "Rockbursts prediction based on rock damage of roof and floor induced by mining," Chinese Journal of Rock Mechanics and Engineering, vol. 31, no. 12, pp. 2438-2444, 2012.

[6] X.-H. Chen, K.-X. Duan, and M.-L. Huang, "Occurrence conditions and criteria of rock burst," Journal of the China Coal Society, vol. 30, supplement, pp. 19-23, 2005.

[7] Z. Wang, J. Zhao, R. Feng, and X. Wen, "Analysis and optimizations on retreating mining measures of rock burst prevention on steeply dipping thick coal seam in deep exploitation," Procedia Engineering, vol. 26, pp. 794-802, 2011 (Chinese).

[8] Y. S. Pan, Z. H. Li, and M. T. Zhang, "Distribution, type, mechanism and prevention of rockburst in China," Chinese Journal of Rock Mechanics and Engineering, vol. 22, no. 11, pp. 1844-1851, 2003.

[9] Y.-D. Jiang, Y.-S. Pan, F.-X. Jiang, L.-M. Dou, and Y. Ju, "State of the art review on mechanism and prevention of coal bumps 
in China," Journal of the China Coal Society, vol. 39, no. 2, pp. 205-213, 2014.

[10] H. P. Kang, J. Lin, and X. Zhang, "Research and application of in-situ stress measurement in deep mines," Chinese Journal of Rock Mechanics and Engineering, vol. 26, no. 5, pp. 929-933, 2007.

[11] J. L. Wu, Elasticity, Higher Education Publishing House, Beijing, China, 2011.

[12] M. Li, X. Mao, Y. Yu, K. Li, C. Ma, and Y. Peng, "Stress and deformation analysis on deep surrounding rock at different time stages and its application," International Journal of Mining Science and Technology, vol. 22, no. 3, pp. 301-306, 2012.

[13] A. Y. Cao, L. M. Dou, R. L. Yan et al., "Classification of microseismic events in high stress zone," Mining Science and Technology (China), vol. 19, no. 6, pp. 718-723, 2009.

[14] X. H. Chen, W. Q. Li, and X. Y. Yan, "Analysis on rock burst danger when fully-mechanized caving coal face passed fault with deep mining," Safety Science, vol. 50, no. 4, pp. 645-648, 2012.

[15] Y.-H. Cheng, F.-X. Jiang, and J.-L. Pang, "Research on lateral strata pressure characteristic in goaf of top coal caving in extra thick coal seam and its application," Journal of the China Coal Society, vol. 37, no. 7, pp. 1088-1093, 2012.

[16] M. G. Qian, X. X. Miao, J. L. Xu, and X. B. Mao, Theory of Key Stratum in Ground Control, China University of Mining and Technology Press, Xuzhou, China, 2010.

[17] L. G. Wang, M. Han, Z. S. Wang et al., "Stress distribution and damage law of mining floor," Journal of Mining \& Safety Engineering, vol. 30, pp. 317-322, 2013.

[18] X.-R. Meng, C.-H. Xu, Z.-N. Gao, and X.-Q. Wang, "Stress distribution and damage mechanism of mining floor," Journal of the China Coal Society, vol. 35, no. 11, pp. 1832-1836, 2010.

[19] H. Shi and F. Jiang, "Study on abutment pressure rule of overlying strata spatial structures based on microseismic monitoring," Chinese Journal of Rock Mechanics and Engineering, vol. 27, pp. 3274-3280, 2008.

[20] L. Xie, L.-M. Dou, C.-G. Lv, G.-L. Yu, and Y. Wang, "Study on the effect of floor burst induced by dynamic disturbance at different lateral pressure coefficients," Journal of Mining \& Safety Engineering, vol. 30, no. 2, pp. 251-255, 2013. 

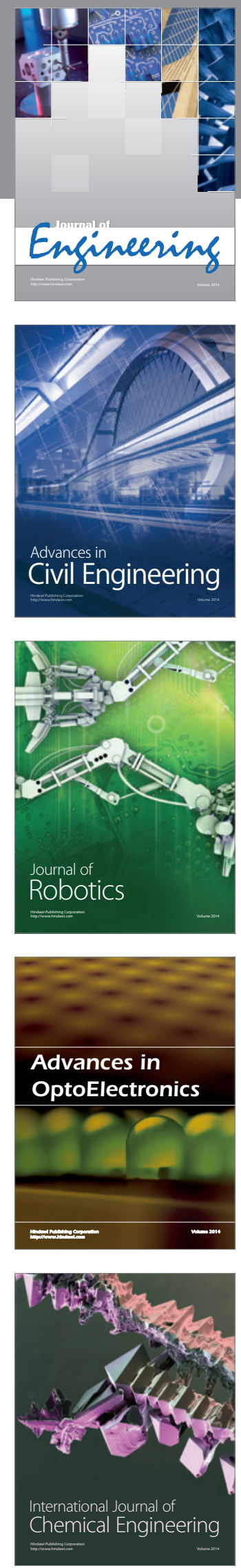

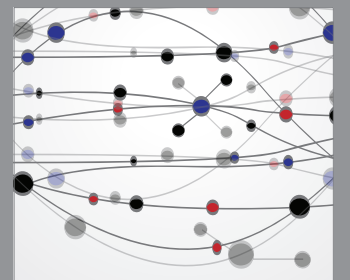

The Scientific World Journal
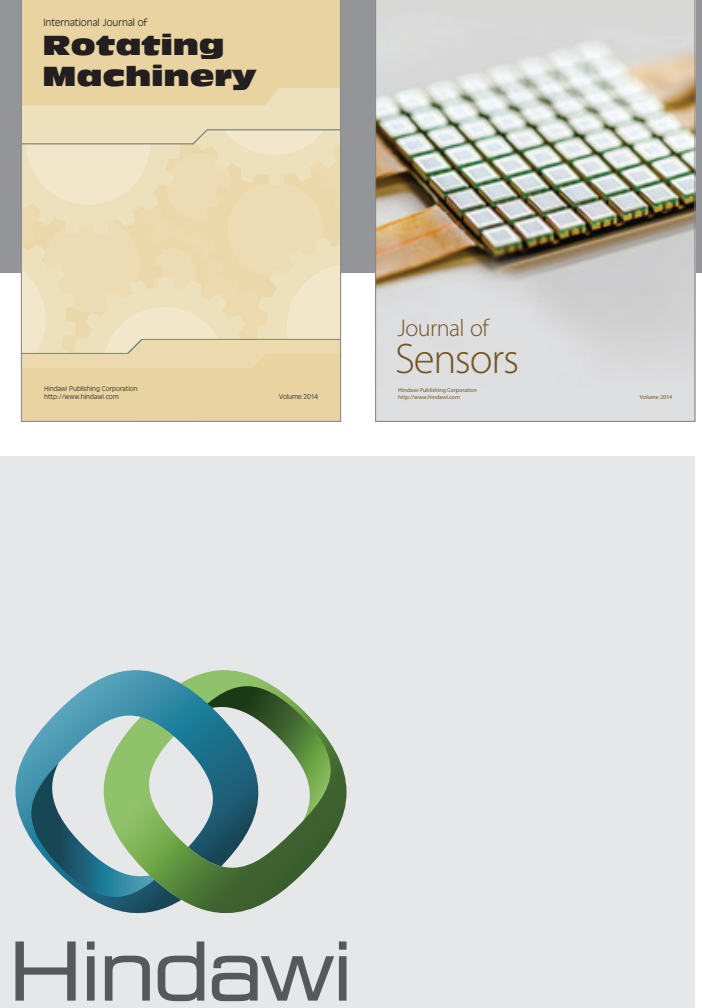

Submit your manuscripts at http://www.hindawi.com
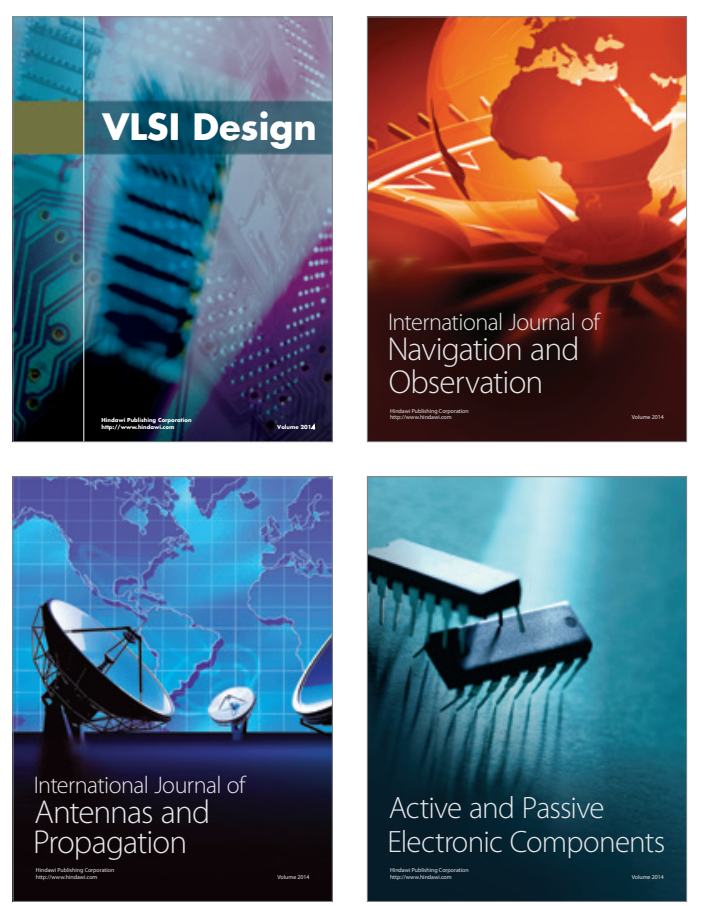
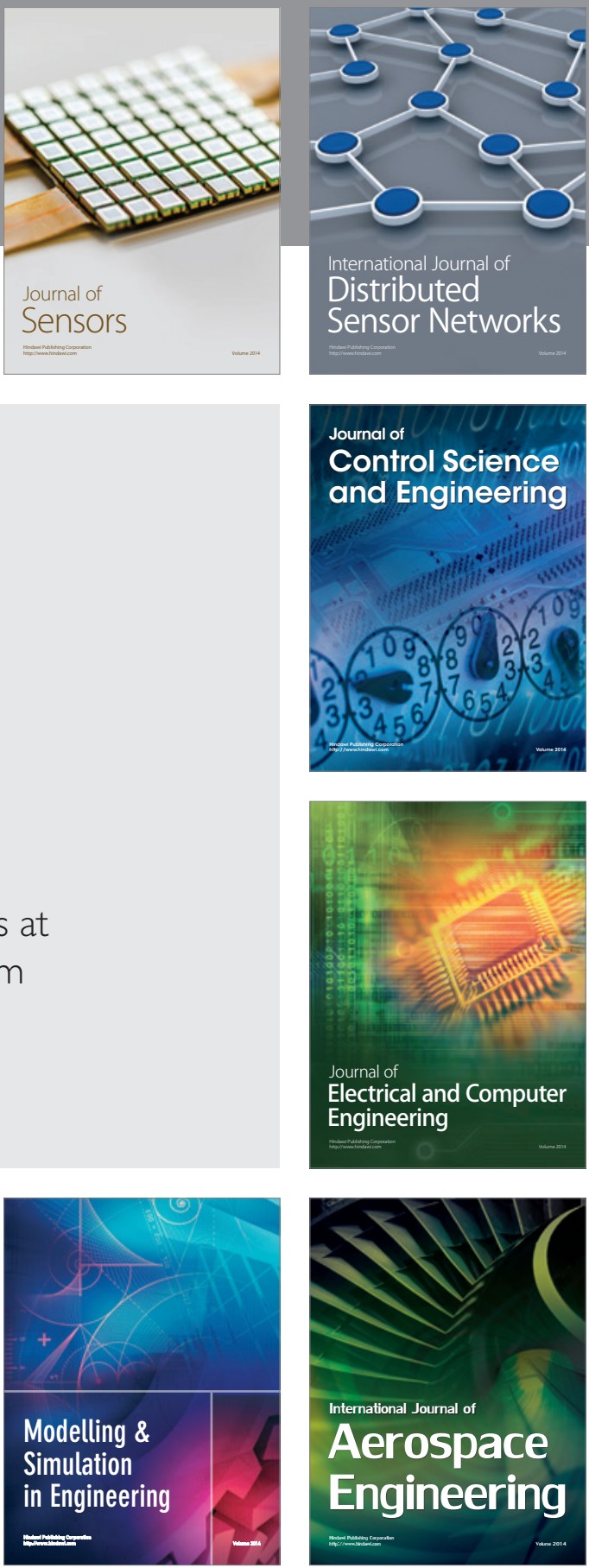

Journal of

Control Science

and Engineering
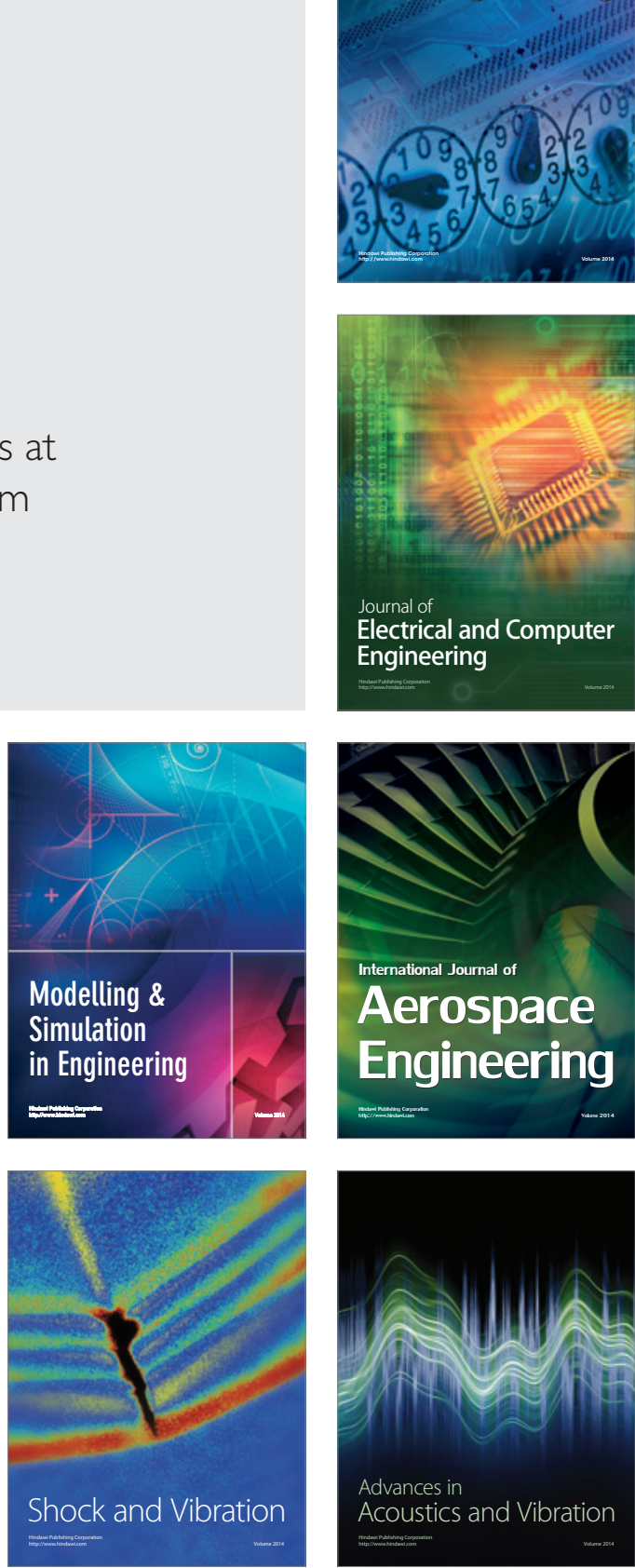